\title{
Chemoresponse after non-curative gastrectomy for M1 gastric cancer
}

\author{
Hyun Beak Shin, Seung Hyoung Lee, Young Gil Son, Seung Wan Ryu and Soo Sang Sohn*
}

\begin{abstract}
Background: M1 gastric cancer has a poor oncologic outcome with a median survival of less than 1 year despite aggressive chemotherapy. Recent trials include chemotherapy combined non-curative gastrectomy. This study evaluated the chemoresponse after non-curative gastrectomy in M1 gastric cancer and the survival benefit.

Methods: Between January 2000 and December 2010, 660 patients received chemotherapy for gastric cancer at the Department of Hemato-Oncology, Dongsan Medical Center, Keimyung University School of Medicine, Daegu, Korea. Data was collected retrospectively from the medical records. Patients who received preoperative or adjuvant chemotherapy, who underwent other surgeries like gastrojejunal bypass or exploratory laparotomy, who died within 3 months due to seriously advanced gastric cancer, who were lost to follow-up, or whose medical records were unsuitable for data collection were excluded. The remaining 101 patients had received chemotherapy only (CTx group, $n=76$ ) or chemotherapy after non-curative gastrectomy (NCG + CTx group, $n=25)$. Clinicopathologic characteristics, chemoresponse, and overall survival were compared between the two groups.

Results: There were no significant differences between the two groups in clinicopathologic characteristics including age, sex, body mass index (BMI), comorbidity, histologic differentiation, tumor location, clinical T stage, and initial site of distant metastasis. Chemoresponse was checked on two separate occasions from the initiation of chemotherapy: first chemotherapy regimen and until the third regimen change. The NCG + CTx group showed more favorable chemoresponse than the CTx group in both checks (60\% and $72 \%$ vs. $18.4 \%$ and $23.7 \%$ ). The NCG + CTx group showed longer overall survival than the CTx group (26 vs. 11 months).
\end{abstract}

Conclusions: Non-curative gastrectomy in M1 gastric cancer could improve chemoresponse and extend overall survival.

Keywords: Chemoresponse, Non-curative gastrectomy, M1 gastric cancer, Chemotherapy, Survival

\section{Background}

M1 gastric cancer is characterized by distant metastasis at sites other than regional lymph node (LN) [1]. Distant metastasis comprises peritoneal metastasis including ovarian metastasis; hematogenous metastasis that spreads to the liver, lung, and bone; and metastasis to distant LNs including paraaortic, neck, and mediastinal LNs.

Chemotherapy has been recommended as a main treatment modality for M1 gastric cancer in the third Japanese gastric cancer treatment guidelines as well as in the 2013 National Comprehensive Cancer Network $(\mathrm{NCCN})$ gastric cancer guidelines [2,3]. However, the median survival of M1 gastric cancer is under 1 year despite aggressive chemotherapy. Although a few clinical trials showed the effectiveness of adjuvant chemotherapy after curative resection in advanced gastric cancer [4-7], the generally poor oncologic outcomes in M1 gastric cancer might be caused by the lack of an outstanding chemotherapeutic agent and definite treatment guidelines specifying surgery [8].

Several study groups have tried to improve the oncologic outcomes with the various new concepts including liver resection for hepatic metastasis from gastric cancer, aggressive surgery with peritonectomy for localized peritoneal metastasis, intraperitoneal chemotherapy, surgery

\footnotetext{
*Correspondence: sohnss@dsmc.or.kr

Department of Surgery, Keimyung University School of Medicine, 194, Dongsan-dong, Choong-gu, Daegu 700-712, Korea
} 
with curative intent in patients who have presented favorable response after chemotherapy, and chemotherapy after non-curative gastrectomy. Some survival benefits were reported [9-24]. But these studies focused on patient survival, although chemoresponse could be the most important mechanism to prolong the survival time after chemotherapy.

With this in mind, we concentrated our attention on the chemoresponse after non-curative gastrectomy in M1 gastric cancer. We hypothesized that non-curative gastrectomy will improve the chemoresponse by reducing tumor burden, similar to other cancers, with noncurative gastrectomy inhibiting the chemoresponse by destroying the lymphatic channels or blood vessels that are the anatomic routes to tumor. Accordingly, the goal was to identify if non-curative gastrectomy could improve the chemoresponse. The influence of chemoresponse on patient survival was assessed.

\section{Methods}

Between January 2000 and December 2010, 660 patients received chemotherapy for gastric cancer at the Department of Hemato-Oncology, Dongsan Medical Center, Keimyung University School of Medicine, Daegu, Korea. We collected the data from this group through a retrospective review of medical records. Patients who received preoperative or adjuvant chemotherapy, who underwent other surgeries like gastrojejunal bypass or exploratory laparotomy, who died within 3 months due to seriously advanced gastric cancer, and who were lost

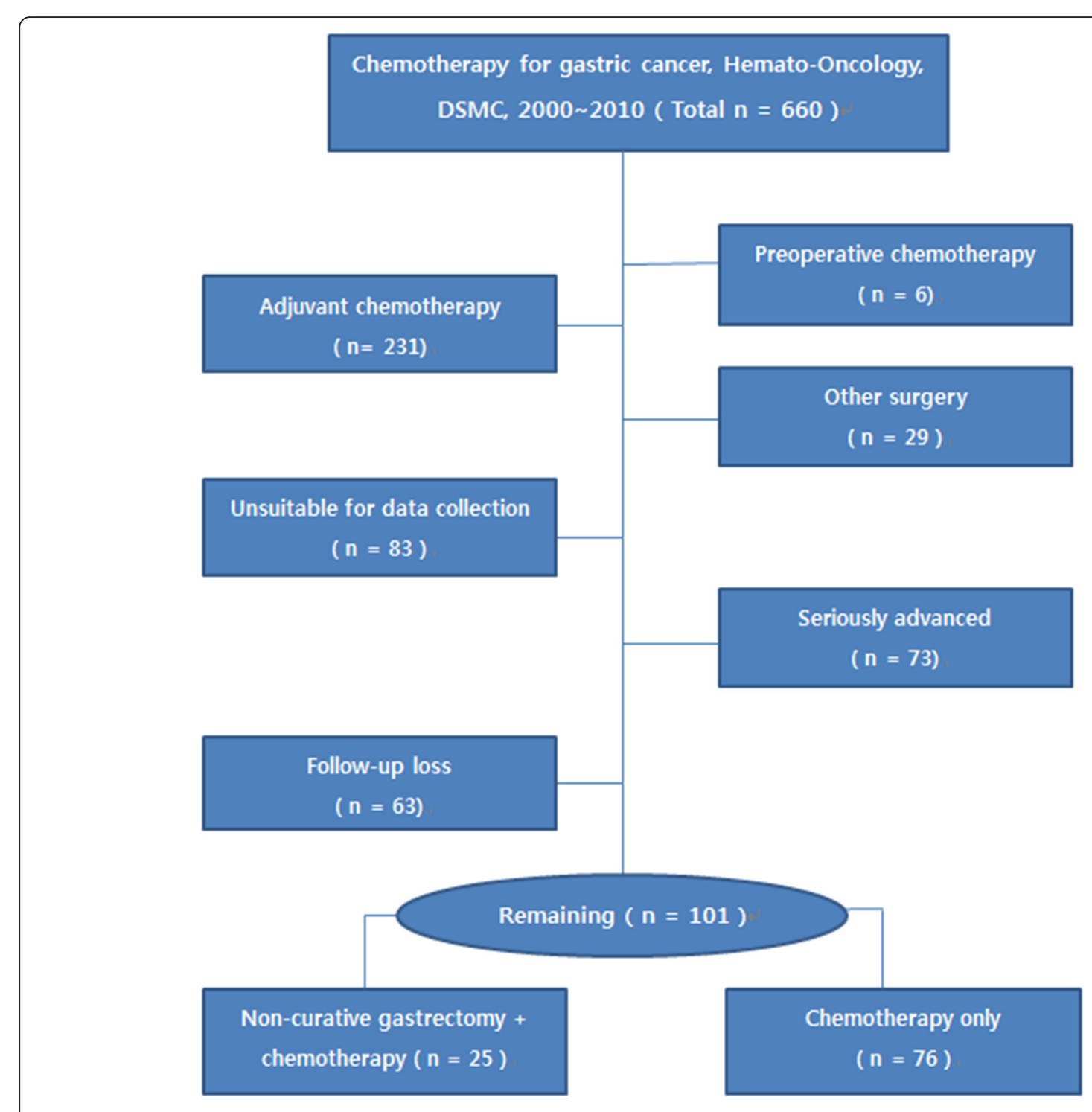

Figure 1 Study design. 
Table 1 Clinicopathologic characteristics

\begin{tabular}{|c|c|c|c|c|}
\hline & & $\begin{array}{l}\text { CTx } \\
(n=76)\end{array}$ & $\begin{array}{l}\text { NCG + CTx } \\
(n=25)\end{array}$ & $P$ value \\
\hline Age, years & Mean (SD) & $53.7( \pm 10.9)$ & $54.3( \pm 11.0)$ & $>0.05$ \\
\hline \multirow[t]{2}{*}{ Sex } & Male & $54(71.1 \%)$ & $18(72.0 \%)$ & $>0.05$ \\
\hline & Female & 22 (28.9\%) & 7 (28.0\%) & \\
\hline $\mathrm{BMI}, \mathrm{kg} / \mathrm{m}^{2}$ & Mean (SD) & $22.0( \pm 3.2)$ & $21.8( \pm 2.2)$ & $>0.05$ \\
\hline Comorbidity & Yes & $14(18.4 \%)$ & $6(24.0 \%)$ & $>0.05$ \\
\hline \multirow[t]{2}{*}{ Histology } & Differentiated & 17 (22.4\%) & 7 (28.0\%) & $>0.05$ \\
\hline & Undifferentiated & 59 (77.6\%) & $18(72.0 \%)$ & \\
\hline \multirow[t]{4}{*}{ Tumor location } & Upper & $11(14.5 \%)$ & 7 (28.0\%) & $>0.05$ \\
\hline & Middle & $13(17.1 \%)$ & 1 (4.0\%) & \\
\hline & Lower & $39(51.3 \%)$ & $13(52.0 \%)$ & \\
\hline & Entire & $13(17.1 \%)$ & $4(16.0 \%)$ & \\
\hline \multirow[t]{2}{*}{ CT stage } & $\mathrm{T} 1 \sim 3$ & 7 (9.2\%) & 7 (28.0\%) & $<0.05$ \\
\hline & T4 & 69 (90.8\%) & 18 (72.0\%) & \\
\hline \multirow[t]{4}{*}{ Initial M1 site } & Peritoneal & 19 (25.0\%) & 15 (60.0\%) & $<0.01$ \\
\hline & Hematogenous & 15 (19.7\%) & $5(20.0 \%)$ & \\
\hline & Distant LN & $24(31.6 \%)$ & $2(8.0 \%)$ & \\
\hline & Mixed & 18 (23.7\%) & $3(12.0 \%)$ & \\
\hline
\end{tabular}

Abbreviation: cT stage clinical T stage, SD standard deviation.

to follow-up, whose medical records were unsuitable for data collection were excluded (Figure 1). The remaining 101 patients had received chemotherapy only (CTx group, $n=76)$ or chemotherapy after non-curative gastrectomy (NCG + CTx group, $n=25)$. Non-curative gastrectomies were comprised of total gastrectomy $(n=15)$ and subtotal gastrectomy $(n=10)$.

There were no significant differences between the two groups in clinicopathologic characteristics including age, sex, body mass index (BMI), comorbidity, histologic differentiation, tumor location, clinical $\mathrm{T}$ stage, and initial site of distant metastasis (Table 1). Chemoresponse and overall survival were compared. In the absence of previously defined criteria for chemoresponse, new criteria were assigned (Figure 2). Patients presenting once with complete response (CR) or partial response (PR) or stable disease (SD) on the Response Evaluation Criteria in Solid Tumors (RECIST) according to clinical progress and follow-up computed tomography $(\mathrm{CT})$, positron emission tomography (PET), bone scan, or magnetic resonance imaging (MRI) from initiation of chemotherapy to the time of evaluation were reclassified as 'favorable chemoresponse.' Otherwise, patients who continued to present progressive disease $(\mathrm{PD})$ until evaluation were reclassified as 'unfavorable chemoresponse'. The clinical course of patients who received palliative chemotherapy for M1 gastric cancer is typically determined following the third change of regimen. Thus, chemoresponse was checked on two separate occasions from the initiation of chemotherapy. One was chemoresponse for the first chemotherapy regimen. The other was chemoresponse until the third regimen change. Overall survival between the two groups was compared. Various regimens were applied for the first chemotherapy as shown in Table 2.

This study was approved by the Institutional Review Board of Keimyung University School of Medicine, Dongsan Medical Center, Daegu, Korea (IRB file no. 2014-01-018).

\section{Statistical analyses}

SPSS version 20.0 (SPSS, Chicago, IL, USA) was used for statistical analyses. To compare the clinicopathologic characteristics and the chemoresponse between the two groups, chi-square test was used for categorical variables, and Student's $t$-test and Fisher's exact test were used for continuous variables. Overall survival was analyzed with the Kaplan-Meier curve analysis, and statistical significance was evaluated with log-rank test. $P<0.05$ was considered significant.

\section{Results}

There were no significant differences in age, sex, BMI, comorbidity, histologic differentiation, and tumor location between the two groups (Table 1). Despite efforts to make the two groups homogenous, clinical T4 gastric

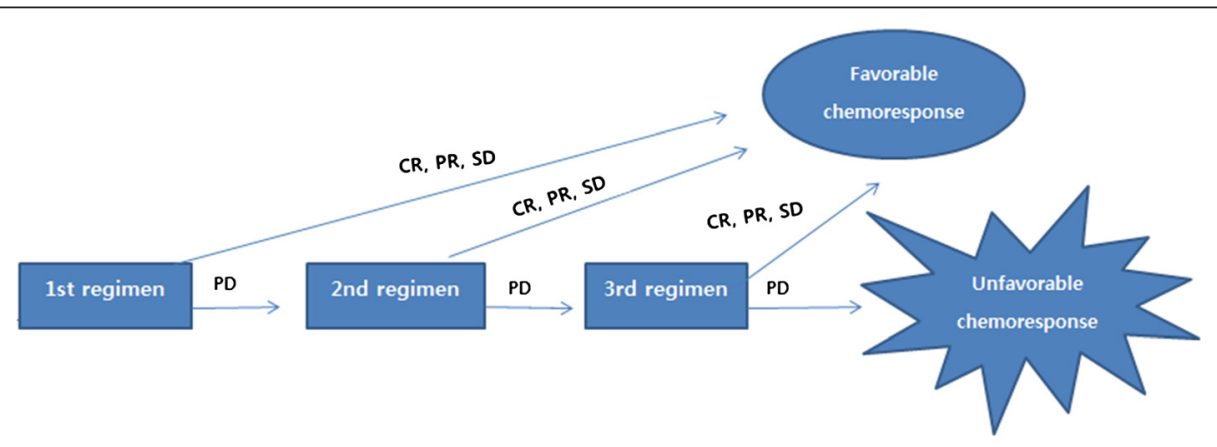

Figure 2 Reclassification of chemoresponse according to the Response Evaluation Criteria in Solid Tumor (RECIST). 
Table 2 Regimens used for the first chemotherapy

\begin{tabular}{|c|c|c|c|}
\hline Regimen & $\begin{array}{l}\text { Total } \\
(n=101)\end{array}$ & $\begin{array}{l}\text { CTx } \\
(n=76)\end{array}$ & $\begin{array}{l}\text { NCG + CTx } \\
(n=25)\end{array}$ \\
\hline Paclitaxel/cisplatin/TS-1 & 27 & 24 & 3 \\
\hline Paclitaxel/cisplatin & 21 & 21 & \\
\hline Capecitabine/cisplatin & 9 & 2 & 7 \\
\hline FOLFOX (folinic acid/5-FU/oxaliplatin) & 7 & 2 & 5 \\
\hline Paclitaxel/TS-1 & 6 & 5 & 1 \\
\hline Irinotecan/cisplatin & 5 & 4 & 1 \\
\hline Docetaxel/oxaliplatin & 5 & 4 & 1 \\
\hline 5-FU/cisplatin & 4 & 3 & 1 \\
\hline Heptaplatin/5-FU & 4 & 4 & \\
\hline FOLFIRI (folinic acid/5-FU/irinotecan) & 3 & 3 & \\
\hline Docetaxel/5-FU/cisplatin & 2 & 2 & \\
\hline TS-1 & 2 & & 2 \\
\hline FOLFOX/cetuximab & 1 & 1 & \\
\hline Capecitabine/lapatinib/eloxatin & 1 & & 1 \\
\hline MFC (MMC/5-FU/cytarabine) & 1 & & 1 \\
\hline Docetaxel/cisplatin & 1 & & 1 \\
\hline TS-1/cisplatin & 1 & & 1 \\
\hline Capecitabine/lapatinib & 1 & 1 & \\
\hline
\end{tabular}

Abbreviations: 5-FU 5-fluorouracil, MMC mitomycin-C, TS-1 tegafur-gimeracil-oteracil potassium.

cancer was somewhat more prevalent in the CTx group. However, considering that serosal exposure of gastric cancer could not be identified directly in this group because there was no operative view and it was difficult to distinguish T4 from T3 in gastric cancer by $\mathrm{CT}$ and PET, this slight difference was disregarded.

The NCG + CTx group displayed a higher proportion of peritoneal metastasis than the CTx group $(60.0 \%$ vs. 25.0\%). Distant LN metastasis was more common in the CTx group (31.6\% vs. $8.0 \%$ ). If we regarded the existence of mixed-type metastasis as being indicative of the aggressiveness of M1 gastric cancer, there was no significant difference in the aggressiveness of cancer between the two groups, because the mixed type metastasis between the two groups displayed no significant difference ( $23.7 \%$ vs. $12 \%, P=0.266$ ).

Based on this result, we compared the chemoresponse and overall survival. The NCG $+\mathrm{CTx}$ group showed more favorable chemoresponse than the CTx group at both checks $(60 \%$ and $72 \%$ vs. $18.4 \%$ and 23.7\%; Table 3). The NCG + CTx group had a longer overall survival than the CTx group (26 vs. 11 months; Table 4, Figure 3).

\section{Discussion}

Presently, patients who received chemotherapy after noncurative gastrectomy for M1 gastric cancer displayed a
Table 3 Chemoresponse according to the change of regimens for chemotherapy

\begin{tabular}{lllll}
\hline Change & Response & $\begin{array}{l}\text { CTx } \\
(\boldsymbol{n}=\mathbf{7 6})\end{array}$ & $\begin{array}{l}\text { NCG + CTx } \\
(\boldsymbol{n}=\mathbf{2 5})\end{array}$ & P value \\
\hline For the first regimen & Favorable & $14(18.4 \%)$ & $15(60.0 \%)$ & $<0.01$ \\
& Unfavorable & $62(81.6 \%)$ & $10(40.0 \%)$ & \\
\multirow{2}{*}{ Until the third regimen } & Favorable & $18(23.7 \%)$ & $18(72.0 \%)$ & $<0.01$ \\
& Unfavorable & $58(76.3 \%)$ & $7(28.0 \%)$ & \\
\hline
\end{tabular}

more favorable chemoresponse and longer overall survival. This result is consistent with the view that noncurative gastrectomy in M1 gastric cancer improves the chemoresponse by reducing the tumor burden [25,26], with minimal inhibited chemoresponse due to destruction of the anatomic route to the tumor during surgery, which lead to prolonged overall survival.

Several previous studies reported that various noncurative surgeries that reduce the tumor burden could produce a survival benefit in M1 gastric cancer [24,27-29]. However, the studies addressed survival after non-curative surgery and not chemoresponse. The significance of the present study was the focus on the relationship between non-curative gastrectomy and chemoresponse.

Generally, it is anticipated that a more favorable chemoresponse after chemotherapy could lead to longer survival. However, how the chemoresponse could influence patient survival in M1 gastric cancer is unclear [30]. This unreliable probability between chemoresponse and survival in M1 gastric cancer might be caused by the lack of an outstanding chemotherapeutic agent. With the development of such an agent, studies demonstrating the oncologic benefit of non-curative gastrectomy would be an important cornerstone for the treatment guideline for M1 gastric cancer.

This study has some limitations. The study was retrospective and the CTx group had no operative view, which could create selection bias and heterogeneity between the two groups. Second, non-curative gastrectomy in itself reduces the tumor burden, which could have overestimated a favorable response. Third, the CTx group displayed marginally more prevalent clinical $\mathrm{T} 4$ gastric cancer, which could be connected to poorer survival. This lack of homogeneity should be considered in overall survival comparative analysis between the two groups. Finally, a quality-of-life evaluation was not

Table 4 Overall survival

\begin{tabular}{lccccc}
\hline Group & $\begin{array}{l}\text { Median } \\
\text { (months) }\end{array}$ & 1-YSR (\%) & 2-YSR (\%) & 3-YSR (\%) & P value \\
\hline CTX & 11 & 40.6 & 16.1 & 4.8 & $<0.01$ \\
NCG + CTX & 26 & 83.4 & 57.1 & 35.6 & \\
\hline
\end{tabular}

Abbreviation: YSR year survival rate. 


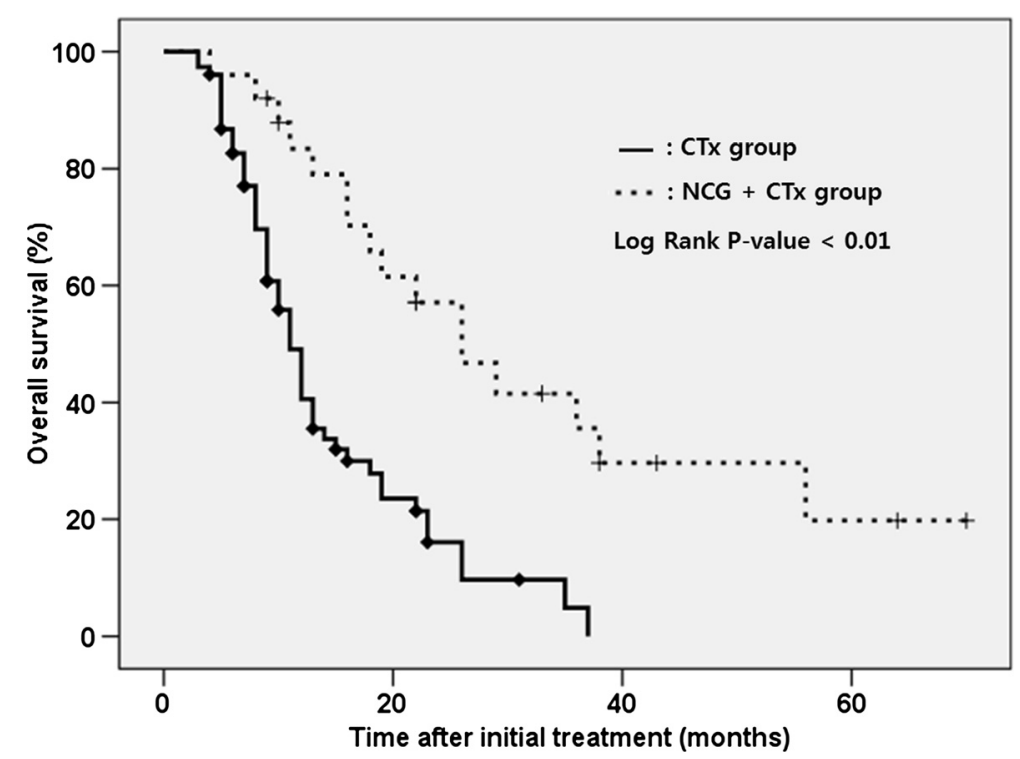

Figure 3 Comparison of overall survival between the NCG + CTx group and the CTx group.

performed. Thus, it is impossible to definitely recommend non-curative gastrectomy, although it is feasible technically.

\section{Conclusions}

Despite the aforementioned limitations due to the heterogeneity between the two groups, non-curative gastrectomy in M1 gastric cancer could improve chemoresponse and extend survival.

\section{Abbreviations}

BMl: Body mass index; CR: Complete response; CT: Computed tomography; CTx: Chemotherapy; CT stage: Clinical T stage; 5-FU: 5-Fluorouracil; LN: Lymph node; MMC: Mitomycin-C; MRI: Magnetic resonance imaging; NCG + CTx: Chemotherapy after non-curative gastrectomy; NCCN: National comprehensive cancer network: PD: Progressive disease; PET: Positron emission tomography; PR: Partial response; RECIST: Response evaluation criteria in solid tumors; SD: Stable disease; SD: Standard deviation; TS-1: Tegafur-gimeracil-oteracil potassium; YSR: Year survival rate.

\section{Competing interests}

The authors declare that they have no competing interests.

\section{Authors' contributions}

HBS helped in the design, analysis, interpretation of data, and drafting of the manuscript. YGS helped in the design, acquisition of data, and critical revision. SHL helped in the design and acquisition of data. SWR and SSS provided critical revision. All authors read and approved the final manuscript.

\section{Acknowledgements}

This article was supported by scholarships from Keimyung University.

Received: 6 June 2014 Accepted: 8 January 2015

Published online: 30 January 2015

\section{References}

1. Japanese Gastric Cancer Association. Japanese classification of gastric carcinoma: 3rd English edition. Gastric Cancer. 2011;14(2):101-12.

2. Association JGC. Japanese gastric cancer treatment guidelines 2010 (ver. 3) Gastric Cancer. 2011;14(2):113-23.
3. Ajani JA, Bentrem DJ, Besh S, D'Amico TA, Das P, Denlinger C, et al. Gastric cancer, version 2.2013: featured updates to the NCCN guidelines. J Natl Compr Canc Netw. 2013;11(5):531-46.

4. Bang YJ, Kim YW, Yang HK, Chung HC, Park YK, Lee KH, et al. Adjuvant capecitabine and oxaliplatin for gastric cancer after D2 gastrectomy (CLASSIC): a phase 3 open-label, randomised controlled trial. Lancet. 2012;379(9813):315-21.

5. Sasako M, Sakuramoto S, Katai H, Kinoshita T, Furukawa H, Yamaguchi T, et al. Five-year outcomes of a randomized phase III trial comparing adjuvant chemotherapy with S-1 versus surgery alone in stage II or III gastric cancer. J Clin Oncol. 2011:29(33):4387-93.

6. Bang YJ, Van Cutsem E, Feyereislova A, Chung HC, Shen L, Sawaki A, et al. Trastuzumab in combination with chemotherapy versus chemotherapy alone for treatment of HER2-positive advanced gastric or gastrooesophageal junction cancer (ToGA): a phase 3, open-label, randomised controlled trial. Lancet. 2010;376(9742):687-97.

7. Sakuramoto S, Sasako M, Yamaguchi T, Kinoshita T, Fujii M, Nashimoto A, et al. Adjuvant chemotherapy for gastric cancer with S-1, an oral fluoropyrimidine. N Engl J Med. 2007;357(18):1810-20.

8. Foukakis T, Lundell L, Gubanski M, Lind PA. Advances in the treatment of patients with gastric adenocarcinoma. Acta Oncol. 2007;46(3):277-85.

9. Bozzetti F, Bonfanti G, Audisio RA, Doci R, Dossena G, Gennari L, et al. Prognosis of patients after palliative surgical procedures for carcinoma of the stomach. Surg Gynecol Obstet. 1987;164(2):151-4.

10. Cheon SH, Rha SY, Jeung HC, Im CK, Kim SH, Kim HR, et al. Survival benefit of combined curative resection of the stomach (D2 resection) and liver in gastric cancer patients with liver metastases. Ann Oncol. 2008;19(6):1146-53.

11. Hioki M, Gotohda N, Konishi M, Nakagohri T, Takahashi S, Kinoshita T. Predictive factors improving survival after gastrectomy in gastric cancer patients with peritoneal carcinomatosis. World J Surg. 2010;34(3):555-62.

12. Kahlke V, Bestmann B, Schmid A, Doniec JM, Kuchler T, Kremer B. Palliation of metastatic gastric cancer: impact of preoperative symptoms and the type of operation on survival and quality of life. World J Surg. 2004;28(4):369-75.

13. Kikuchi S, Arai $Y$, Morise $M$, Kobayashi $N$, Tsukamoto $H$, Shimao $H$, et al. Gastric cancer with metastases to the distant peritoneum: a 20-year surgical experience. Hepatogastroenterology. 1998:45(22):1183-8.

14. Kim KW, Chow O, Parikh K, Blank S, Jibara G, Kadri H, et al. Peritoneal carcinomatosis in patients with gastric cancer, and the role for surgical resection, cytoreductive surgery, and hyperthermic intraperitoneal chemotherapy. Am J Surg. 2014;207(1):78-83.

15. Kunisaki C, Shimada H, Akiyama H, Nomura M, Matsuda G, Ono H. Survival benefit of palliative gastrectomy in advanced incurable gastric cancer. Anticancer Res. 2003:23(2C):1853-8. 
16. Li C, Yan M, Zhu ZG. Nonpalliative surgical resection for gastric cancer patients with distant metastasis. J Invest Surg. 2012;25(2):100-6.

17. Miner TJ, Jaques DP, Karpeh MS, Brennan MF. Defining palliative surgery in patients receiving noncurative resections for gastric cancer. J Am Coll Surg. 2004;198(6):1013-21.

18. Saidi RF, ReMine SG, Dudrick PS, Hanna NN. Is there a role for palliative gastrectomy in patients with stage IV gastric cancer? World J Surg. 2006;30 (1):21-7.

19. Sakamoto Y, Ohyama S, Yamamoto J, Yamada K, Seki M, Ohta K, et al. Surgical resection of liver metastases of gastric cancer: an analysis of a 17-year experience with 22 patients. Surgery. 2003;133(5):507-11.

20. Sougioultzis S, Syrios J, Xynos ID, Bovaretos N, Kosmas C, Sarantonis J, et al Palliative gastrectomy and other factors affecting overall survival in stage IV gastric adenocarcinoma patients receiving chemotherapy: a retrospective analysis. Eur J Surg Oncol. 2011;37(4):312-8.

21. Yan TD, Yonemura Y, Morris DL. Surgical strategies for gastric cancer with synchronous peritoneal carcinomatosis (Br J Surg 2006; 93: 1530-1535). Br J Surg. 2007;94(5):642. author reply 642-643.

22. Glockzin G, Schlitt HJ, Piso P. Peritoneal carcinomatosis: patients selection, perioperative complications and quality of life related to cytoreductive surgery and hyperthermic intraperitoneal chemotherapy. World I Surg Oncol. 2009;7:5.

23. Ojima H, Ootake S, Yokobori T, Mochida Y, Hosouchi Y, Nishida Y, et al. Treatment of multiple liver metastasis from gastric carcinoma. World I Surg Oncol. 2007;5:70.

24. Novotny AR, Reim D, Friess HM, Schuhmacher C. Secondary gastrectomy for stage IV gastroesophageal adenocarcinoma after induction-chemotherapy. Langenbecks Arch Surg. 2014;399(6):773-81.

25. Bonenkamp JJ, Sasako M, Hermans J, van de Velde CJ. Tumor load and surgical palliation in gastric cancer. Hepatogastroenterology. 2001;48 (41):1219-21.

26. Pollock RE, Roth JA. Cancer-induced immunosuppression: implications for therapy? Semin Surg Oncol. 1989;5(6):414-9.

27. Zhang JZ, Lu HS, Huang CM, Wu XY, Wang C, Guan GX, et al. Outcome of palliative total gastrectomy for stage IV proximal gastric cancer. Am J Surg. 2011;202(1):91-6.

28. Hartgrink HH, Putter H, Klein Kranenbarg E, Bonenkamp JJ, van de Velde CJ. Value of palliative resection in gastric cancer. Br I Surg. 2002;89(11):1438-43.

29. Koga S, Kawaguchi H, Kishimoto H, Tanaka K, Miyano Y, Kimura O, et al. Therapeutic significance of noncurative gastrectomy for gastric cancer with liver metastasis. Am J Surg. 1980;140(3):356-9.

30. An JY, Kim HI, Cheong JH, Hyung WJ, Kim CB, Noh SH. Pathologic and oncologic outcomes in locally advanced gastric cancer with neoadjuvant chemotherapy or chemoradiotherapy. Yonsei Med J. 2013;54(4):888-94.

\section{Submit your next manuscript to BioMed Central and take full advantage of:}

- Convenient online submission

- Thorough peer review

- No space constraints or color figure charges

- Immediate publication on acceptance

- Inclusion in PubMed, CAS, Scopus and Google Scholar

- Research which is freely available for redistribution 